\title{
Adenoviruses associated with acute gastroenteritis in hospitalized and community children up to 5 years old in Rio de Janeiro and Salvador, Brazil
}

\section{Correspondence \\ José Paulo G. Leite jpgleite@ioc.fiocruz.br}

Received 19 April 2006 Accepted 9 October 2006
Edson Pereira Filho, ${ }^{1,2}$ Nieli R. da Costa Faria, ${ }^{2}$ Alexandre M. Fialho, ${ }^{2}$ Rosane S. de Assis, ${ }^{2}$ Marilda Maria S. Almeida, ${ }^{2}$ Myrna Rocha, ${ }^{3}$ Márcia Galvão, ${ }^{4}$ Flávia B. dos Santos, ${ }^{2}$ Maurício L. Barreto ${ }^{5}$ and José Paulo G. Leite ${ }^{2}$

${ }^{1}$ Subdivisão de Pesquisa, Instituto de Biologia do Exército, Rua Francisco Manuel 102, Benfica, Rio de Janeiro, RJ, CEP 20911-270, Brazil

${ }^{2}$ Departamento de Virologia, Instituto Oswaldo Cruz, Fundação Oswaldo Cruz, Avenida Brasil 4365 - Pavilhão Cardoso Fontes, Manguinhos, Rio de Janeiro, RJ, CEP 21045-900, Brazil

${ }^{3}$ Setor de Pediatria, Hospital Municipal Jesus, Rua Oito de Dezembro 717, Vila Isabel, Rio de Janeiro, RJ, CEP 20550-200, Brazil

${ }^{4}$ Setor de Pediatria, Hospital Municipal Salles Neto, Praça Condessa Paulo de Frontin 52, Rio Comprido, Rio de Janeiro, RJ, CEP 20260-010, Brazil

${ }^{5}$ Instituto de Saúde Coletiva, Universidade Federal da Bahia, Rua Padre Feijó 29, Canela, Salvador, BA, CEP 40110-170, Brazil

Acute gastroenteritis is a major source of morbidity and mortality among young children in developed and developing countries. Human adenoviruses ( $\mathrm{HAdVs}$ ), and in particular species $\mathrm{F}$, are related to childhood diarrhoea worldwide. This study presents the results obtained during an investigation of HAdVs causing acute gastroenteritis in children hospitalized in Rio de Janeiro, RJ, Brazil, from April 1996 to September 2003, as well as in children with diarrhoea living in the slums of Salvador, BA, Brazil, from October 2001 to September 2003. A total of 3060 stool samples was analysed by an enzyme immunoassay for rotavirus and adenovirus (EIARA) and 61 ( $2 \%$ ) were found to be positive. HAdV presented with low prevalence throughout the year, with a slight but not significant increase in incidence in late summer and early autumn. Children up to 2 years of age were the most frequently affected ( $79 \%$ of all positive samples). All positive samples were analysed further by generic and species-specific HAdV PCR protocols, confirming $100 \%$ specificity of this rapid and inexpensive EIARA. Species $F$ was the most prevalent $(65 \%)$, despite the occurrence of species $A(12 \%), C, D$ and co-infection F/D (5\% each) and species $B$ and co-infections F/A, F/C and B/D ( $2 \%$ each). In order to type the species F strains as HAdV-40 or -41 , generic PCR and a Hinfl restriction digest were performed. HAdV-40 and -41 were found to represent $62 \%(23 / 37)$ and $38 \%(14 / 37)$, respectively. These results demonstrated that a combination of generic and species-specific PCRs is useful and reliable for HAdV species and type identification directly from faecal specimens. The results confirmed the endemism of human adenoviruses, mainly species $F$, in children as aetiological agents of diarrhoea, although the limited sensitivity of EIARA as a screening method may have underestimated their prevalence.
Abbreviations: EIARA, enzyme immunoassay for rotavirus and adenovirus; HAdV, human adenovirus.

The GenBank/EMBL/DDBJ accession numbers for the hexon gene sequences of the HAdV-41 samples determined in this work are D0504432-D0504434.

\section{INTRODUCTION}

Human adenoviruses (HAdVs) are one the major causes of a number of different clinical syndromes including gastroenteritis, respiratory disease, conjunctivitis, haemorrhagic cystitis and exanthema (Horwitz, 2001). They comprise 51 different serotypes (HAdV-1 to -51) grouped into 6 species, A to F (de Jong et al., 1999). 
Acute infectious diarrhoea is a common disease in young children throughout the world. Estimated incidence rates in developing countries range from 2.1 to 3.8 episodes per child per year for children between 11 and 48 months (Kosek et al., 2003). In Brazil, diarrhoea presents one of the principal morbidity indexes and causes of mortality in the first year of life (http://w3.datasus.gov.br/datasus/ datasus.php).

Identification of HAdV species or serotypes can be achieved, with different degrees of efficiency, by serotype-specific neutralization tests (Hierholzer, 1995) and restriction endonuclease analysis of DNA extracted from infected cells (Wadell et al., 1980; Allard et al., 2001). The results of these methods, although of epidemiological value, are often of limited clinical usefulness, as up to 30 days may be required for complete characterization following the initial isolation of HAdV in cell culture. Alternative identification methods therefore have been developed and include the use of serotype-specific monoclonal antibodies (Adam et al., 1996; Wood et al., 1997), detection of species-specific antibodies (Akalu et al., 1998) and PCR-based identification protocols (Akalu et al., 1998; Xu et al., 2000). Two recent advances, species-specific PCR (Pring-Årkeblom et al., 1999) and generic PCR for human adenoviruses (Allard et al., 2001), may facilitate the rapid and accurate diagnosis of adenovirus infection in clinical specimens.

In Brazil, a few reports have described HAdV infection in children with gastroenteritis, demonstrating the involvement of adenoviruses in cases of acute infantile gastroenteritis (Leite et al., 1985; Pereira et al., 1993; Harsi et al., 1995; Soares et al., 2002).

The main objective of the present report was to investigate and characterize HAdV species in cases of acute gastroenteritis in children hospitalized in Rio de Janeiro, RJ, Brazil, and in children living in the slums of Salvador, BA, Brazil, using two molecular protocols for the detection and characterization of these viruses directly from clinical specimens.

\section{METHODS}

Subjects, specimens and adenovirus screening. The study population consisted of children up to 5 years of age with acute diarrhoea who attended two public hospitals in Rio de Janeiro, in the south-eastern region of Brazil, from April 1996 to September 2003, and children up to 5 years of age presenting with diarrhoea and living in the slums of Salvador, in the north-eastern region of Brazil, from October 2001 to September 2003. The hospitalized children in Rio de Janeiro were more severely dehydrated compared with those living in the poor communities in Salvador, who were assisted at home.

A total of 2452 faecal samples were collected from the two public hospitals in Rio de Janeiro and 608 were collected from children living in the slums in Salvador. Only one specimen was collected per child. The faecal specimens were collected and maintained at $2-8{ }^{\circ} \mathrm{C}$ and sent to the Laboratório de Virologia Comparada, Departamento de Virologia, Instituto Oswaldo Cruz, and stored at $-20^{\circ} \mathrm{C}$ for viral testing.
This project was approved by the Ethical Research Committee of the Hospital Municipal Jesus and by the Instituto de Saúde Coletiva, Universidade Federal da Bahia.

Virus prototypes, virus isolation and indirect immunofluorescence assay. Lyophilized aliquots of adenovirus types 4 (species E), 6 (species C), 7 (species B), 9 (species D), 12 (species A) and HAdV-40 strain Dugan and HAdV-41 strain Tak (species F), provided by the Virus Reference Laboratory, Central Public Health Laboratory, Colindale, London, UK, were used as prototype strains. Lyophilized aliquots were reconstituted in $150 \mu \mathrm{l}$ Dulbecco's minimum essential medium (Gibco-BRL Life Technologies) and used as sample patterns (positive controls).

Prototype strains and negative samples for the PCR were inoculated (0.1 ml per tube) onto HEK-293 cells (kindly provided by Dr Jean Claude D'Halluin, INSERM, France) at $70 \%$ confluence, as described previously (Leite et al., 1985).

Supernatants from infected cells showing a positive cytopathic effect were tested by fluorescent antibody technique (Light Diagnostics; Chemicon International) according to the manufacturer's recommendations and by generic and species-specific PCRs, as described by Allard et al. (2001) and Pring-Årkeblom et al. (1999), respectively.

Enzyme immunoassay for rotavirus and adenovirus (EIARA). Faecal suspensions $(10 \%, \mathrm{w} / \mathrm{v})$ were prepared in $0.01 \mathrm{M}$ Tris/ $\mathrm{Ca}^{2+}$ buffer ( $\mathrm{pH}$ 7.2), as described by Leite et al. (1985), and clarified by centrifugation at $2000 \mathrm{~g}$ for $5 \mathrm{~min}$. Supernatants were submitted to screening with a commercial EIARA test according to the manufacturer's recommendations (BioManguinhos-Fiocruz). The sensitivity and specificity of the EIARA test in faecal specimens has been established previously (Pereira et al., 1985) and is largely used in Brazil by the Ministry of Health as the standard method for rotavirus and adenovirus detection.

HAdV detection and characterization. Virus DNA was extracted from $250 \mu 10 \%$ faecal suspension and from the supernatant of cell cultures infected with the HAdV prototype strains using the QIAmp DNA mini kit according to the manufacturer's instructions (Qiagen).

Generic and species-specific primers and PCR amplification tests for HAdV were performed as described by Allard et al. (2001) and PringÅrkeblom et al. (1999), respectively. Amplicons were resolved on a $2 \%$ agarose gel by electrophoresis. Restriction endonuclease digestion to discriminate between HAdV-40 and - 41 was performed as described by Allard et al. (2001). For molecular procedures, four separate rooms were used to avoid cross-contamination of samples. Milli-Q water was used as a negative control in all procedures.

DNA purification, sequencing and phylogenetic analysis. Amplicons were purified using a QIAquick PCR purification kit (Qiagen). DNA sequencing was performed by dideoxynucleotide chain termination using the ABI Prism BigDye Terminator cycle sequencing ready reaction kit (PE Applied Biosystems). Sequence editing, analysis and multiple alignments were performed using BioEdit (Hall, 1999). Phylogenetic analysis was conducted using MEGA 2.1 (Kumar et al., 2001).

\section{RESULTS}

Of the 3060 faecal samples from children up to 5 years of age with acute gastroenteritis, 61 (2\%) were positive for HAdV by EIARA, comprising 44 of the 2452 faecal samples from hospitalized children in Rio de Janeiro (1.8\%) and 17 of the 608 samples from the children living in the slums of Salvador $(2.8 \%)$. 
From the 61 faecal samples positive by EIARA, 59 were available in sufficient amounts for testing by PCR. All 59 $(100 \%)$ were positive by the generic PCR for human adenoviruses and 57 (97\%) by the species-specific PCR. Four samples were initially negative for species-specific PCR but positive by generic PCR for human adenoviruses. These samples were inoculated onto HEK-293 cells and two were found to be positive and characterized as species $\mathrm{C}$, probably due to the increased virus concentration.

The species-specific multiplex PCR showed non-specific amplicons when the assay was carried out with HAdV species prototypes (A-F) (Fig. 1a), as well as with positive samples. In order to check the origin of these non-specific amplicons, we performed nucleotide alignments between the primers and the nucleotide hexon region of species A-F (GenBank accession nos NC_001460, NC_004001, NC_001405, NC_002067, NC_003266 and NC_001454, respectively). The analysis, using CLUSTAL $\mathrm{W}$ software (Thompson et al., 1994; www.ebi.ac.uk/clustalw), showed the possibility of cross-hybridization among the different primers, corroborating the unexpected results obtained with the HAdV prototypes (data not shown). To resolve this problem, amplification was carried out using an individual set of primers for each species (Fig. 1b). Electrophoretic analyses of species F multiplex PCR amplicons and PCR using individual sets of primers are also shown (Fig. 1c, d). Using this methodology, species $\mathrm{F}(65 \%)$ was the most prevalent, followed by species A $(12 \%), \mathrm{C}, \mathrm{D}$ and coinfection $\mathrm{F} / \mathrm{D}(5 \%$ each) and species $\mathrm{B}$ and co-infections F/A, F/C and B/D (2\% each). Similar percentages for the prevalence of HAdV species $F$ were observed in both hospitalized children and those living in slums.

To characterize the enteric HAdV species $F$, the amplicon of $301 \mathrm{bp}$ obtained with the generic PCR for HAdVs was subjected to RFLP analysis using the restriction endonuclease HinfI (Invitrogen). Using this methodology, HAdV40 was characterized in 23/37 species F-positive samples $(62 \%)$ and $14(38 \%)$ were characterized as HAdV-41 (Fig. 2). The $301 \mathrm{bp}$ amplicons of four samples were chosen randomly for sequencing: strains of HAdV-41 from Rio de Janeiro (samples 929 and 934, GenBank accession nos DQ504432 and DQ504433, respectively) and Salvador (sample 1139, GenBank accession no. DQ504434), and an HAdV-40 strain from Rio de Janeiro (sample 2795). The sequence analysis corresponded to the $253 \mathrm{nt}$ at positions 47-299 within the hexon gene. The Brazilian strains showed $100 \%$ nucleotide homology among the three HAdV-41 Brazilian strains and $97 \%$ with the HAdV-41 prototype Tak (GenBank accession no. X51783) and with isolate Vaalriver (GenBank accession no. AJ608285). The HAdV-40 Brazilian strain showed $100 \%$ nucleotide homology with the HAdV40 prototype strain Dugan (GenBank accession no. X51782) (Fig. 3).

Case distribution according to age group showed that $45 / 57$ (79\%) of the children aged up to 2 years presented species $\mathrm{F}$ (a)

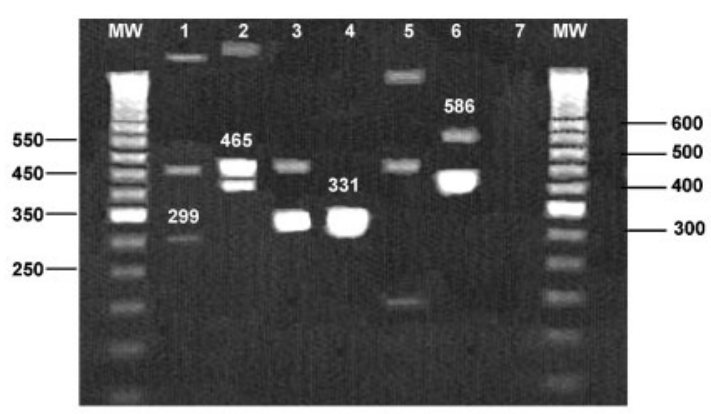

(b)

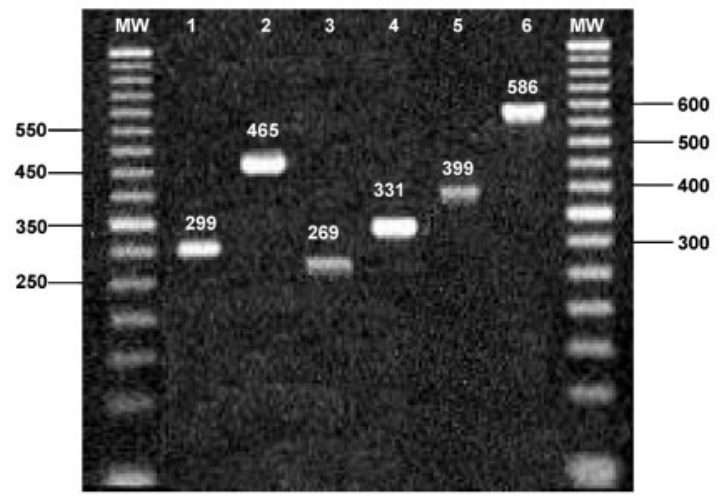

(c)

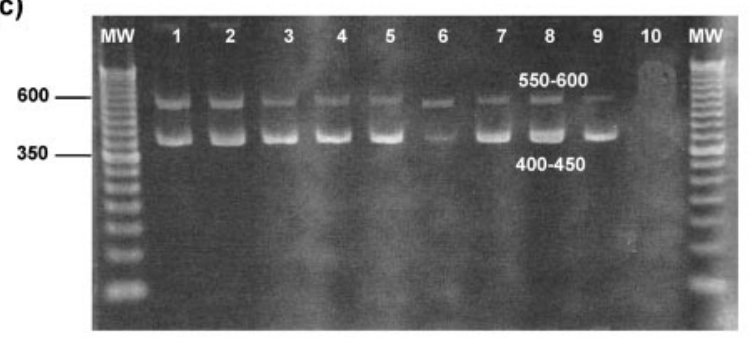

(d)

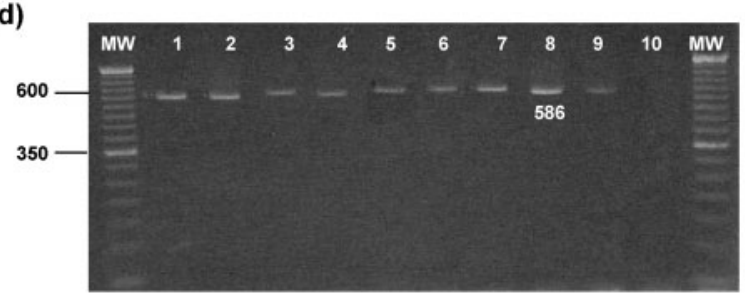

Fig. 1. Detection of adenovirus genotypes using speciesspecific PCRs. ( $a, b)$ Detection of prototype viruses using multiplex PCR (a) and PCR using individual primers for each species (b). Lanes: 1, HAdV-A; 2, HAdV-B; 3, HAdV-C; 4, HAdV-D; 5, HAdV-E; 6, HAdV-F; 7, negative control. (c, d) Detection of HAdV species $F$ using species multiplex PCR (c) and PCR using individual primers for species $F(d)$. Lanes 1-9 show sample amplicons. Lanes: 1 , sample 929; 2, sample 934; 3 , sample $139 ; 4$, sample $1412 ; 5$, sample $1595 ; 6$, sample 2346; 7, sample 2501; 8, sample 2530; 9, sample 2790; 10, negative control. MW, 50 bp DNA ladder size marker. 


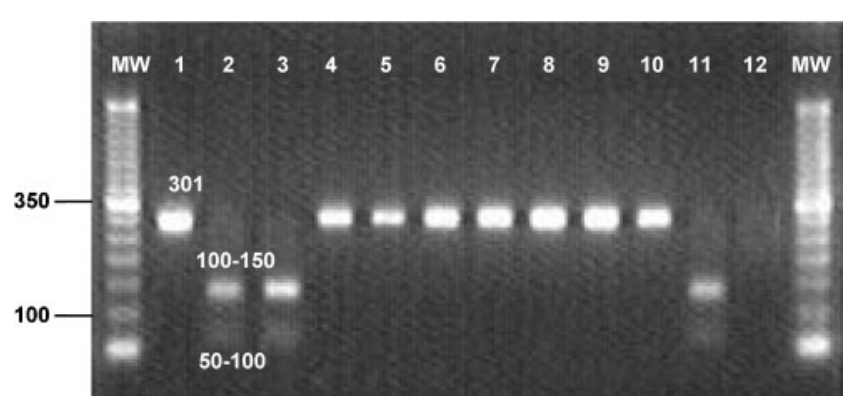

Fig. 2. Characterization of HAdV-40 and -41 by Hinfl endonuclease digestion. The prototype virus restriction fragments are shown in lanes 1 (HAdV-40 strain Dugan) and 2 (HAdV-41 strain Tak). HAdV-41 sample restriction fragments are shown in lanes 3 (sample 929) and 11 (sample 934). Lanes 4-10 show HAdV-40 sample restriction fragments (samples 1412, 896, 1595, 2501, 2795, 3118 and 6006, respectively) and lane 12 shows the restriction endonuclease-negative control. MW, 50 bp DNA ladder size marker.

as the main species observed, corresponding to $31 / 45$ positive cases $(69 \%)$ from the entire study.

The monthly distribution of the accumulated positive cases during the study showed that the period from February to April contributed to $36 / 57$ (63\%) of the positive cases, and April was the only month where HAdV was observed annually (data not shown). No pattern of serotype distribution was observed, although peaks of HAdV-40 and -41 were observed in March and April, respectively (Fig. 4).

\section{DISCUSSION}

Gastroenteritis represents one of the main problems of paediatric public health in developing countries, second only to acute respiratory infection as the most important cause of infant morbidity and mortality in these countries. In Brazil, acute diarrhoea is one of the most common diseases in childhood, responsible for $15 \%$ of deaths among children (Scaletsky et al., 1999; Linhares, 2002). Faecal samples from children up to 5 years of age who had been

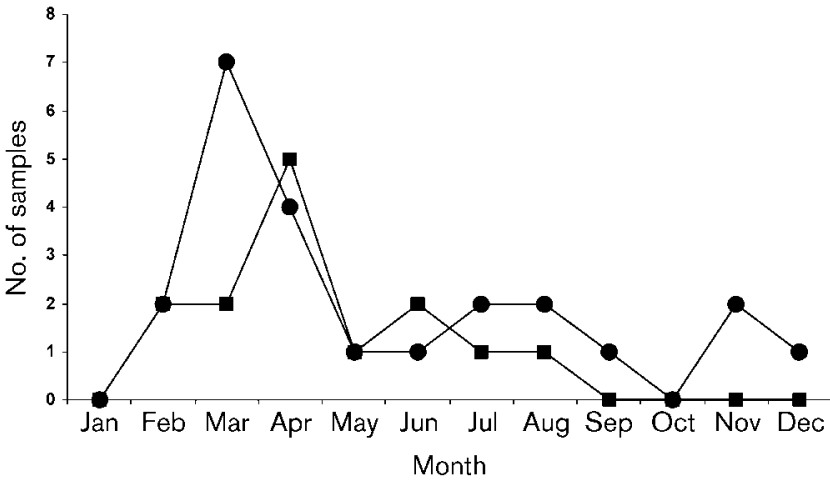

Fig. 4. Seasonal distribution of adenovirus species $F$ during the period studied. The number of samples represents the monthly distribution of the accumulated positive cases during the study. $\bullet$, HAdV40; $\mathbf{\square}, \mathrm{HAdV} 41$.

hospitalized in Rio de Janeiro or were living in the slums of Salvador were screened by EIARA and HAdV species were characterized using two PCR methodologies. A total of 61 (2\%) of 3060 samples were positive for HAdV by EIARA screening, indicating a low prevalence of HAdV. A higher percentage of HAdV detection might have been obtained if a more sensitive methodology, such as an amplification assay, had been used as a screening test (Rohayem et al., 2004). Of the EIARA-positive samples that were available in sufficient amounts to allow testing by PCR, $100 \%$ were positive using the generic PCR for human adenoviruses. In contrast, species-specific PCR (either multiplex or singleplex) (PringÂrkeblom et al., 1999) should not be used for HAdV screening, as the sensitivity ( $97 \%$ ) was lower compared with the generic PCR and EIARA. Reports from other countries associating HAdV with acute gastroenteritis range from 2.3 to $38 \%$ (Herrmann et al., 1988; Lew et al., 1991; McIver et al., 2001; Marie-Cardine et al., 2002). Studies in other Brazilian cities have found higher rates of HAdV: Leite $e$ t al. (1985) found $5.2 \%$ in Rio de Janeiro, Harsi et al. (1995) found $10 \%$ in São Paulo and Soares et al. (2002) found $4.9 \%$ in four Brazilian cities. However, our results are similar to those described by Pereira et al. (1993) in a report

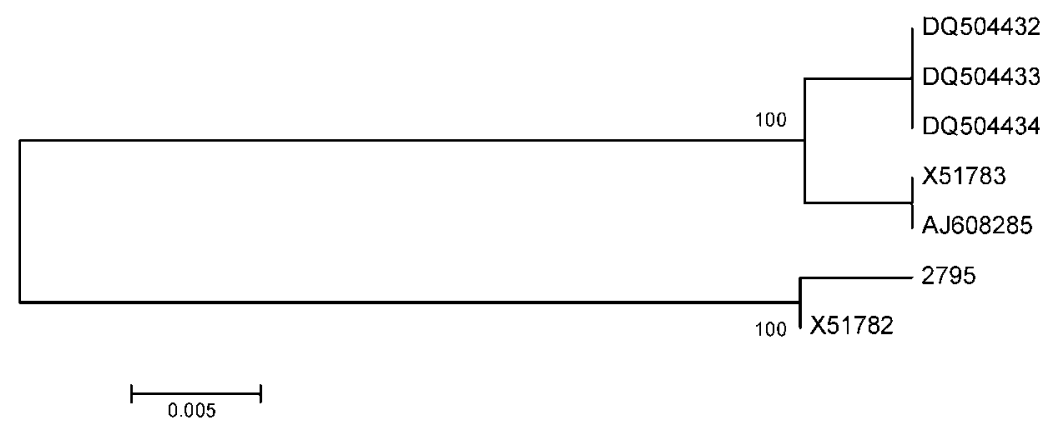

Fig. 3. Neighbour-joining phylogenetic tree based on partial nucleotide sequences of the adenovirus hexon gene of HAdV-41 [GenBank accession nos X51783 (strain Tak), AJ608285 (isolate Vaalriver), DQ504432 (sample 929), DQ504433 (sample 934) and DQ504434 (sample 1139)] and HAdV-40 [GenBank accession no. X51782 (strain Dugan) and sample 2795]. Numbers adjacent to the nodes represent the percentage bootstrap support (1000 replicates). Bar, 0.005 nucleotide substitutions per site. 
on an HAdV and rotavirus surveillance programme in 14 Brazilian States from 1984 to 1989.

Species F (HAdV-40 and -41) was the most prevalent HAdV, corresponding to $37 / 57$ positive samples $(65 \%)$. Similar percentages of HAdV species $\mathrm{F}$ were observed in hospitalized children and those living in slums. Hospitalization of children living in slums was probably avoided due to the oral rehydration therapy provided at the start of their symptoms.

These results are similar to those obtained by Uhnoo et al. (1984) and higher than previous reports where HAdV species $\mathrm{F}$ has been found to be responsible for $2-40 \%$ of positive cases (Herrmann et al., 1988; Lew et al., 1991; Saderi et al., 2002; Oh et al., 2003). In countries like Sweden, Thailand, Korea, the USA, the UK, Australia, France, Iran and Argentina, prevalence of enteric adenovirus from 1.55 to $15 \%$ has been observed, compared with the prevalence found in our study of $1.2 \%$ (37/3060) (Uhnoo et al., 1984; Herrmann et al., 1988; Kim et al., 1990; Lew et al., 1991; Barnes et al., 1998; Bon et al., 1999; Saderi et al., 2002; Bereciartu et al., 2002; Amar et al., 2004; Chen et al., 2005; Liu et al., 2006; Venacchio et al., 2006). In Brazil, Soares et al. (2002) found a similar prevalence $(1.55 \%)$ of enteric HAdV in four Brazilian cities.

In a specific comparison of the results of enteric HAdV species $\mathrm{F}$ from studies performed in Brazil, the $65 \%$ positive samples in this study was higher than the $36 \%$ obtained by Leite et al. (1985) and the $32 \%$ obtained by Soares et al. (2002). In the present study, HAdV-40 and -41 contributed to $62 \%(23 / 37)$ and $38 \%(14 / 37)$ of positive samples, respectively. The results obtained here used PCR followed by restriction endonuclease digestion to characterize species F; Soares et al. (2002) used monoclonal antibodies for HAdV40 or -41 and detected $50 \%$ HAdV-40 (11/22) and $27 \%$ HAdV-41 (6/22), whilst $23 \%(5 / 22)$ were recognized indistinctly as HAdV-40/41. This suggests that the higher level of species $\mathrm{F}$ detection is a direct result of the improvement in the techniques of viral characterization (McIver et al., 2001), as it has been demonstrated previously that the monoclonal antibodies for enteric adenovirus (EAdV) are highly specific reagents that can fail to detect genomic variations of EAdV, probably due to the alteration of external neutralizing epitopes under immunological pressure (Scott-Taylor et al., 1990).

Comparing the results of the present study with those of Soares et al. (2002) from February 1998 to July 2000, both carried out in Rio de Janeiro, we detected a lower percentage $(0.86 \%)$ of positive samples for HAdV compared with their result of $2.7 \%$, although we observed a greater percentage of HAdV species F ( $89 \%$ ) compared with their result of $47 \%$, possibly due to the larger number of inpatients involved in the current study.

In an analysis of the age group of HAdV infection, we observed that $79 \%(45 / 57)$ of positive cases were in children under 2 years of age and species $\mathrm{F}$ was present in 31/45
(69\%) of the cases studied. Our data reveal a greater percentage of positive cases than previously described in the literature, which showed that species $\mathrm{F}$ was prevalent in approximately $50 \%$ of adenovirus-positive samples. Taken together, these results show that EAdV plays an important role in acute diarrhoeal infection (Uhnoo et al., 1984; Kim et al., 1990; Dennehy et al., 2001; Saderi et al., 2002; Bereciartu et al., 2002; Oh et al., 2003).

With regard to other species of HAdV associated with cases of gastroenteritis, we observed the presence of species A (12\%), C, D and co-infection F/D (5\% each) and species B and co-infections F/A, F/C and B/D (2\% each). These results are similar to previous reports that have described other species of adenovirus that could be associated with acute gastroenteritis, particularly HAdV-12, -18 and -31 (species A), HAdV-3 and -7 (species B), and HAdV-1, -2 and -5 (species C) (Brown et al., 1984; Uhnoo et al., 1984; Leite et al., 1985; Gomes et al., 1989; Brown, 1990).

The monthly distribution of the accumulated number of positive samples studied by species-specific PCR showed a greater prevalence in the number of cases between February and April and highlighted the month of April as the only month with positive cases in 7 years of study (Fig. 4). Unfortunately, the number of samples was too small to draw any significant conclusions about the seasonality of adenovirus infection. Dennehy et al. (2001) described the occurrence of low rates throughout the year, Barnes et al. (1998) observed the existence of random peaks during the year and de Jong et al. (1993) observed that HAdV species F occurred more frequently at the beginning of autumn. Jarecki-Khan et al. (1993) found prevalence peaks of EAdV in dry months, which corresponded to winter. McIver et al. (2001), in Australia, observed that species $\mathrm{F}$ infection increased from February to April. Comparing our results with those of Soares et al. (2002) in Rio de Janeiro, in spite of no evidence for seasonal variation of EAdV in their study, they observed peaks of HAdV-40 and -41 in March and May, respectively. In the current study, similar results were found and peaks of HAdV-40 and -41 were observed in March and April, respectively (Fig. 4).

Mixed infections were found in the present work, which can be explained by the fact that some viruses from a particular episode continue to be excreted while another virus causes the acute disease. In any individual case, determining which aetiological agent is the cause of gastroenteritis can be difficult (Oh et al., 2003). The identified HAdV in the sample should not necessarily be considered to be the causative agent of the infection, as infections caused by members of species $\mathrm{C}$ and HAdV-3 can result in lingering intermittent excretion in the faeces after a previous infection (Pring-Årkeblom et al., 1999; Allard et al., 2001).

The combination of generic PCR for human adenoviruses (Allard et al., 2001) and the species-specific PCR (PringÅrkeblom et al., 1999) are tools available for use in the molecular characterization of HAdV, and have the advantage 
that they can be used to test clinical specimens directly compared with other methodologies that require virus isolation in cell culture prior to identification.

Continuous studies are essential to verify the impact of HAdV in the community and compare this with hospitalization cases, as well as investigating the seasonality of these viruses compared with rotaviruses, astroviruses and human caliciviruses. In association with potential sanitary and health-care improvements, continuous investigations will become increasingly important with the introduction of the rotavirus vaccine campaign in 2006 in Brazil and probably in other South American countries.

\section{ACKNOWLEDGEMENTS}

This work was supported by the Conselho Nacional de Desenvolvimento Científico e Tecnológico (CNPq), Fundação Oswaldo Cruz (Fiocruz), Coordenação Geral de Laboratórios de Saúde Pública (CGLAB/SVS/MS) and Instituto de Biologia do Exército (IBEx). We thank Dr Marcos Bryan Heinemann for help with the phylogenetic analysis, Silvana A. R. Portes for assistance with the immunofluorescence assay and Dr Marize Pereira Miagostovich for critical reading of the manuscript.

\section{REFERENCES}

Adam, E., Nasz, I. \& Lengyel, A. (1996). Characterization of adenovirus hexons by their epitope composition. Arch Virol 141, 1891-1907.

Akalu, A., Seidel, W., Liebermann, H., Bauer, U. \& Döhner, L. (1998). Rapid identification of subgenera of human adenovirus by serological and PCR assays. J Virol Methods 71, 187-196.

Allard, A., Albinsson, B. \& Wadell, G. (2001). Rapid typing of human adenoviruses by a general PCR combined with restriction endonuclease analysis. J Clin Microbiol 39, 498-505.

Amar, C. F. L., East, C., Maclure, E., McLauchlin, J., Jenkins, C., Duncanson, P. \& Wareing, D. R. A. (2004). Blinded application of microscopy, bacteriological culture, immunoassays and PCR to detect gastrointestinal pathogens from faecal samples of patients with community-acquired diarrhoea. Eur J Clin Microbiol Infect Dis 23, 529-534.

Barnes, G. L., Uren, E., Stevens, K. B. \& Bishop, R. F. (1998). Etiology of acute gastroenteritis in hospitalized children in Melbourne, Australia, from April 1980 to March 1993. J Clin Microbiol 36, 133-138.

Bereciartu, A., Bok, K. \& Gómez, J. (2002). Identification of viral agents causing gastroenteritis among children in Buenos Aires, Argentina. J Clin Virol 25, 197-203.

Bon, F., Fascia, P., Dauvergne, M., Tenenbaum, D., Planson, H., Petion, A. M., Pothier, P. \& Kohli, E. (1999). Prevalence of group A rotavirus, human calicivirus, astrovirus, and adenovirus type 40 and 41 infections among children with acute gastroenteritis in Dijon, France. J Clin Microbiol 37, 3055-3058.

Brown, M. (1990). Laboratory identification of adenoviruses associated with gastroenteritis in Canada from 1983 to 1986. J Clin Microbiol 28, 1525-1529.

Brown, M., Petric, M. \& Middleton, P. J. (1984). Diagnosis of fastidious enteric adenoviruses 40 and 41 in stool specimens. J Clin Microbiol 20, 334-338.
Chen, K.-T., Chen, P.-Y., Tang, R.-B., Huang, Y.-F., Lee, P.-I., Yang, J.-Y., Chen, H.-I., Bresee, J., Hummelman, E. \& Glass, R. (2005). Sentinel hospital surveillance for rotavirus diarrhea in Taiwan, 2001-2003. J Infect Dis 192 (Suppl. 1), S44-S48.

de Jong, J. C., Bijlsma, K., Wermenbol, A. G., Verweij-Uijterwaal, M. W., van der Avoort, H. G. A. M., Wood, D. J., Bailey, A. S. \& Osterhaus, A. D. M. E. (1993). Detection, typing, and subtyping of enteric adenoviruses 40 and 41 from fecal samples and observation of changing incidences of infections with these types and subtypes. $J$ Clin Microbiol 31, 1562-1569.

de Jong, J. C., Wermenbol, A. G., Verweij-Uijterwaal, M. W., Slaterus, K. W., Wertheim-Van Dillen, P., Van Doormum, G. J., Khoo, S. H. \& Hierholzer, J. C. (1999). Adenoviruses from human immunodeficiency virus-infected individuals, including two strains that represent new candidate serotypes Ad50 and Ad51 of species B1 and D, respectively. J Clin Microbiol 37, 3940-3945.

Dennehy, P. H., Nelson, S. M., Spangenberger, S., Noel, J. S., Monroe, S. S. \& Glass, R. I. (2001). A prospective case-control study of the role of astrovirus in acute diarrhea among hospitalized young children. J Infect Dis 184, 10-15.

Gomes, S. A., Candeias, J. A., Monteiro, S. P., Pereira, H. G. \& Niel, C. (1989). New genome types of adenovirus types 1,3 , and 5 isolated from stools of children in Brazil. J Clin Microbiol 27, 1022-1026.

Hall, T. A. (1999). BioEdit: a user-friendly biological sequence alignment editor and analysis program for Windows 95/98/NT. Nucleic Acids Symp Ser 41, 95-98.

Harsi, C. M., Rolim, D. P., Gomes, S. A., Gilio, A. E., Stewien, K. E., Baldacci, E. R. \& Candeias, J. A. (1995). Adenovirus genome types isolated from stools of children with gastroenteritis in Sao Paulo, Brazil. J Med Virol 45, 127-134.

Herrmann, J. E., Blacklow, N. R., Perron-Henry, D. M., Clements, E., Taylor, D. N. \& Echeverria, P. (1988). Incidence of enteric adenovirus among children in Thailand and the significance of these viruses in gastroenteritis. J Clin Microbiol 26, 1783-1786.

Hierholzer, J. (1995). Adenoviruses. In Diagnostic Procedures for Viral, Rickettsial and Chlamydial Infections, 7th edn, pp. 169-188. Edited by E. H. Lennette, D. A. Lennette \& E. T. Lennette. Washington, DC: American Public Health Association.

Horwitz, M. S. (2001). Adenoviruses. In Fields Virology, 4th edn, pp. 2301-2326. Edited by D. M. Knipe, M. Howley, D. E. Griffin, R. A. Lamb, M. A. Matin, B. Roizman \& S. E. Straus. Philadelphia, PA: Lippincott Williams \& Wilkins.

Jarecki-Khan, K., Tzipori, S. R. \& Unicomb, L. E. (1993). Enteric adenovirus infection among infants with diarrhea in rural Bangladesh. J Clin Microbiol 31, 484-489.

Kim, K.-H., Yang, J.-M., Joo, S.-I., Cho, Y.-G., Glass, R. I. \& Cho, Y.-J. (1990). Importance of rotavirus and adenovirus types 40 and 41 in acute gastroenteritis in Korean children. J Clin Microbiol 28, 2279-2284.

Kosek, M., Bern, C. \& Guerrant, R. L. (2003). The global burden of diarrhoeal disease, as estimated from studies published between 1992 and 2000. Bull World Health Organ 81, 197-204.

Kumar, S., Tamura, K., Jakobsen, I. B. \& Nei, M. (2001). MEGA2: molecular evolutionary genetics analysis software. Bioinformatics $\mathbf{1 7}$, 1244-1245.

Leite, J. P., Pereira, H. G., Azeredo, R. S. \& Schatzmayr, H. G. (1985). Adenoviruses in faeces of children with acute gastroenteritis in Rio de Janeiro, Brazil. J Med Virol 15, 203-209.

Lew, J. F., Moe, C. L., Monroe, S. S., Allen, J. R., Harrison, B. M., Forrester, B. D., Stine, S. E., Woods, P. A., Hierholzer, J. C. \& Herrmann, J. E. (1991). Astrovirus and adenovirus associated with diarrhea in children in day care settings. J Infect Dis 164, 673-678. 
Linhares, A. L. (2002). Vacina contra rotavírus em Belém, Pará: bases epidemiológicas, inocuidade, imunogenicidade e eficácia, p. 199. Instituto Evandro Chagas, Fundação Nacional de Saúde.

Liu, C., Grillner, L., Jonsson, K., Linde, A., Shen, K., Lindell, A. T., Wirgart, B. Z. \& Johansen, K. (2006). Identification of viral agents associated with diarrhea in young children during a winter season in Beijing, China. J Clin Virol 35, 69-72.

Marie-Cardine, A., Gourlain, K., Mouterde, O., Castignolles, N., Hellot, M. F., Mallet, E. \& Buffet-Janvresse, C. (2002). Epidemiology of acute viral gastroenteritis in children hospitalized in Rouen, France. Clin Infect Dis 34, 1170-1178.

Mclver, C. J., Hansman, G., White, P., Doultree, J. C., Catton, M. \& Rawlinson, W. D. (2001). Diagnosis of enteric pathogens in children with gastroenteritis. Pathology 33, 353-358.

Oh, D.-Y., Gaedicke, G. \& Schreier, E. (2003). Viral agents of acute gastroenteritis in German children: prevalence and molecular diversity. J Med Virol 71, 82-93.

Pereira, H. G., Azeredo, R. S., Leite, J. P., Andrade, Z. P. \& De Castro, L. (1985). A combined enzyme immunoassay for rotavirus and adenovirus (EIARA). J Virol Methods 10, 21-28.

Pereira, H. G., Linhares, A. C., Candeias, J. A. \& Glass, R. I. (1993). National laboratory surveillance of viral agents of gastroenteritis in Brazil. Bull Pan Am Health Organ 27, 224-233.

Pring-Årkeblom, P., Trijssenaar, J. F. E., Adrian, T. \& Hoyer, H. (1999). Multiplex polymerase chain reaction for subgenus-specific detection of human adenoviruses in clinical samples. J Med Virol 58, 87-92.

Rohayem, J., Berger, S., Juretzek, T., Herchenröder, O., Mogel, M., Poppe, M., Henker, J. \& Rethwilm, A. (2004). A simple and rapid single-step muliplex PCR RT-PCR to detect Norovirus, Astrovirus and Adenovirus in clinical stool samples. J Virol Methods 118, 49-59.

Saderi, H., Roustai, M. H., Sabahi, F., Sadeghizadeh, M., Owlia, P. \& de Jong, J. C. (2002). Incidence of enteric adenovirus gastroenteritis in Iranian children. J Clin Virol 24, 1-5.
Scaletsky, I. C., Pedroso, M. Z., Morais, M. B., Carvalho, R. L., Silva, R. M., Fabbricotti, S. H. \& Fagundes-Neto, U. (1999). Association of patterns of Escherichia coli adherence to HEp-2 cells with acute and persistent diarrhea. Arq Gastroenterol 36, 54-60 (in Portuguese).

Scott-Taylor, T., Ahluwalia, G., Klisko, B. \& Hammond, G. W. (1990). Prevalent enteric adenovirus variant not detected by commercial monoclonal antibody enzyme immunoassay. J Clin Microbiol 28, 2797-2801.

Soares, C. C., Volotão, E. M., Albuquerque, M. C., da Silva, F. M., de Carvalho, T. R., Nozawa, C. M., Linhares, R. E. \& Santos, N. (2002). Prevalence of enteric adenoviruses among children with diarrhea in four Brazilian cities. J Clin Virol 23, 171-177.

Thompson, J. D., Higgins, D. G. \& Gibson, T. J. (1994). CLUSTAL W: improving the sensitivity of progressive multiple sequence alignment through sequence weighting, position-specific gap penalties and weigh matrix choice. Nucleic Acids Res 22, 4673-4680.

Uhnoo, I., Wadell, G., Svensson, L. \& Johansson, M. E. (1984). Importance of enteric adenoviruses 40 and 41 in acute gastroenteritis in infants and young children. J Clin Microbiol 20, 365-372.

Venacchio, L., Vezina, R. M., Mitchell, A. A., Lesko, S. M., Plaut, A. G. \& Acheson, D. W. (2006). Diarrhea in American infants and young children in the community setting: incidence, clinical presentation and microbiology. Pediatr Infect Dis J 25, 2-7.

Wadell, G., Hammarskjold, M. L., Winberg, G., Varsanyi, T. M. \& Sundell, G. (1980). Genetic variability of adenoviruses. Ann NY Acad Sci 354, 16-42.

Wood, S. R., Sharp, I. R., Caul, E. O., Paul, I., Bailey, A. S., Hawkins, M., Pugh, S., Treharne, J. \& Stevenson, S. (1997). Rapid detection and serotyping of adenovirus by direct immunofluorescence. $J$ Med Virol 51, 198-201.

Xu, W., McDonough, M. C. \& Erdman, D. D. (2000). Species-specific identification of human adenoviruses by a multiplex PCR assay. J Clin Microbiol 38, 4114-4120. 